\title{
Modelling and analysis of four wheel rim by using PEEK composites
}

\begin{abstract}
Wheel plays a vital role of vehicle suspension which guides the static and dynamic load during vehicle action. Four wheeler should withstand the load while carries the heavy load of occupants considering self weight also. So that the automotive industries mostly exploring the polymeric material in order to get lesser weight without substantial loss in vehicle quality and reliability. Even though the conventional materials are used for preparing the rim has good mechanical properties but it suffers from serious disadvantage of the less weight to strength ratio and low life. This reduction of weight of a vehicle directly impacts its fuel consumption. To achieve this weight reduction the material used for manufacturing the wheel rim should be the composite materials with the identical or superior mechanical properties than the conventional rims. The materials used are Polyether ether ketone (PEEK) materials which are expressed as polyether ether ketone. In this project, analysis of the Car wheel rim is carried out for weight reduction. The wheel rim is modeled by using standard parameters in Creo Parametric 2.0 software and analyzed to see the variations of deformation and stresses of the rim for different material such as Aluminium Alloy, PEEK, PEEK with 30\% Glass fiber, PEEK-90 HMF 20, PEEK-90 HMF 40 after the static structural analysis is done using the ANSYS 17.0 software. The analysis is carried using ANSYS for different compositions of the PEEK materials. The results such as deformation, vonmisesstress, life and maximum shear stress of the different PEEK materials are obtained for different four wheeler rim materials. The results of materials are compared with one another and the one with best mechanical properties is considered as the alternate material for the conventional rim wheel. Using this method, the life cycle of the rim was enhanced to $1 * 10 \mathrm{e} 6$ meet their design requirement. On analysis by implementing different PEEK composites we find that PEEK-90 HMF 20 suits the best for manufactured the wheel rim material.
\end{abstract}

Keywords: peek composites, wheel rim, modelling
Volume 2 Issue 6 - 2018

Manivannan R, Rajasekar R, Gobinath VK

Department of Mechanical Engineering, Kongu Engineering College, India

Correspondence: Rajasekar R, Department of Mechanica Engineering, Kongu Engineering College, Tamil Nadu- 638060, India, Tel +919629797069, Email manimach019@gmail.com

Received: June 01, 2018 | Published: November 09, 2018

\section{Introduction}

The wheel is a part that permits efficient movement of an object across a surface where there is a force pressing the object to the surface. The spoke wheel rim assembly contributes the major weight addition in motorcycle after engine. To overcome this disadvantage alloy wheels are invented. While comparing all alloy materials aluminium alloy is the best of other alloy materials. ${ }^{1}$ The automotive industry faces increasing pressure to maximize performance while minimizing weight and cost to produce more fuel efficient vehicles. Composite materials: A new kind of material which is formed due to combination of two or more metals or nonmetals is known as composite materials. Generally composite materials are lighter and stronger than conventional metals. Thermoplastic composite materials consist of thermoplastic resins as matrix, reinforcement with traditional fibers as thermo sets matrix. They have shown great promise as materials for current and future automotive, aerospace and industrial applications. Composite material wheel is different from the light alloy wheel, ${ }^{2,3}$ and it is developed mainly for low weight. However, this wheel has inadequate consistency against heat and for best strength. PEEK (polyether ether ketone) polymer continues to successfully replace steel, aluminium, bronze, titanium, and other high-performance materials, because it offers an ideal combination of mechanical, thermal and aluminium spokes logical properties, combined with excellent resistance to grease, oils, acids and all other automotive fluids. PEEK is an ideal replacement for Aluminium alloy. PEEK is particularly useful in the automobile industry for its weight. Their Types are 1. PEEK 2. PEEK with 30\% Glass fiber, 2. PEEK-90 HMF 20\% Carbon fiber and 3. PEEK-90 HMF 40\% Carbon fiber.

\section{Problem identification:}

While considering conventional wheel rim the following problems were identified

a. The weight of the conventional wheel rim is relatively high

b. Rims made of metals and metal alloys are highly prone to corrosion

c. Manufacturing of the rims involves high consumption of time and requires more man power

d. Machining process of conventional rim is more complicate and requires high skilled workers to do the operation.

e. Metals are highly prone to temperature changes as they expand on hot conditions and shrink on cold conditions

f. It is difficult to identify the small deformation in the conventional rim caused due to sudden impact.

g. Costs of the metal rims are comparatively high. 


\section{Objectives}

a. To be a perfect alternative material for manufacturing wheel rims are PEEK-90 HMF 20

b. To resist deformations and changes caused due to temperature changes

c. To withstand corrosion caused by different conditions of environment

d. To be a material of light weight

e. To be a material of high availability and less cost.

\section{Material selection}

\section{Peek}

a. PEEK stands for Polyether ether ketone

b. Polyether ether ketone is a colourless organic thermoplastic polymer in the polyaryletherketone family

c. PEEK is a semi crystalline thermoplastic with excellent mechanical and chemical resistance properties

d. PEEK polymers are obtained by step-growth polymerization by the alkylation of bi-phenolate salts (Table 1) (Table 2).

Table I Material Properties

\begin{tabular}{lllllll}
\hline SI No & Mechanical property & Aluminum Alloy & PEEK & PEEK GF 30 & PEEK 90 HMF 20 & PEEK 90 HMF 40 \\
\hline I & Density $\left(\mathrm{kg} / \mathrm{m}^{3}\right)$ & 2685 & 1520 & 1320 & 1370 & 1450 \\
2 & Young's Modulus (MPa) & 69000 & 4060 & 4100 & 22000 & 4500 \\
3 & Poisson's Ratio & 0.33 & 0.45 & 0.46 & 0.4556 & 0.48 \\
4 & Tensile Yield Strength (MPa) & 229 & 190 & 100 & 280 & 330 \\
5 & Compressive Yield Strength (MPa) & 250 & 118 & 95 & 270 & 310 \\
6 & Tensile Ultimate Strength (MPa) & 279 & 100 & 100 & 100 & 100 \\
\hline
\end{tabular}

Table 2 Design of wheel rim

\begin{tabular}{lll}
\hline SI No & Specification & Value \\
\hline I & Rim Width & $215.9 \mathrm{~mm}$ \\
2 & Wheel Diameter & $480 \mathrm{~mm}$ \\
3 & Offset & $128 \mathrm{~mm}$ \\
& & \\
4 & Pitch Circle Diameter(PCD) & $110 \mathrm{~mm}$ \\
5 & Centre Base Diameter (CBD) & 70 \\
6 & Rim thickness & 7 \\
7 & Bolt diameter & 10 \\
8 & Number of bolt holes & 5 \\
\hline
\end{tabular}

\section{Modelling}

There are many software packages are available for creating the $3 \mathrm{D}$ model of the car wheel rim and some of the software's are
a. Creo Parametric
b. Solid Works
c. Catia
d. Unigraphics
e. Inventor

\section{Purpose}

Here we have chosen the Creo parametric as the modelling software because of following advantages.

a. It is the feature based modelling software (Figure 1)
b. Associativity
c. Parametric based design
d. Easy to design intricate shapes

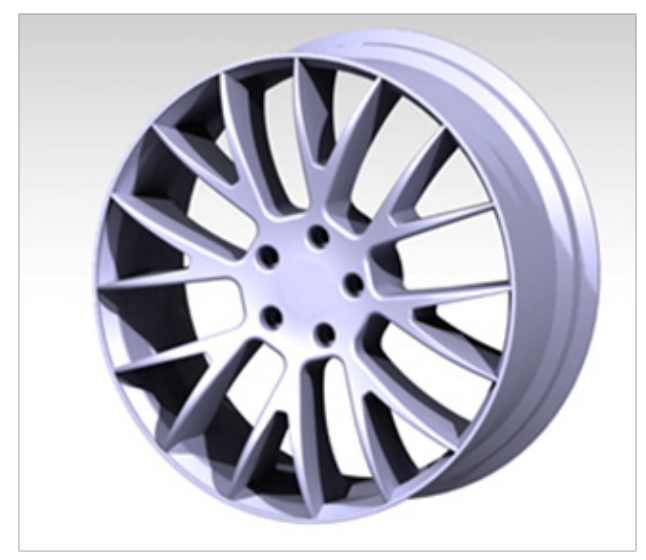

Figure I Creo Parametric model of Rim.

\section{Fem analysis of wheel rim}

\section{Procedure for analysis}
a. Build the model
b. Apply loads and obtain the solution.
c. Expand the modes.
d. Review the results. 


\section{Meshing the Model:}

\section{Boundary Conditions}

From the following Table 3, we can calculate the Angular velocity of the wheel rim. ${ }^{4-8}$

$V=r \times \omega$

Where, $\mathrm{V}=75 \mathrm{~km} / \mathrm{hr}=20.83 \mathrm{~m} / \mathrm{s}$

$\mathrm{r}=240 \mathrm{~mm}=0.24 \mathrm{~m}$

$20.83=0.24 \times \omega$

$\omega=86.79 \mathrm{rad} / \mathrm{s}$

Table 3 Parameters used for static steady

\begin{tabular}{llll}
\hline SI No & Parameters & Symbols & Data \\
\hline I & Velocity of car & V & $70 \mathrm{~km} / \mathrm{hr}$ \\
2 & Radius of Rim & R & $240 \mathrm{~mm}$ \\
3 & Tire pressure & pi & $303.4 \mathrm{KPa}$
\end{tabular}

To get deformation and stress, a load is applied on the circumference of wheel rim and fixed on the bolt holes of the wheel rim which is shown in Figure 2.

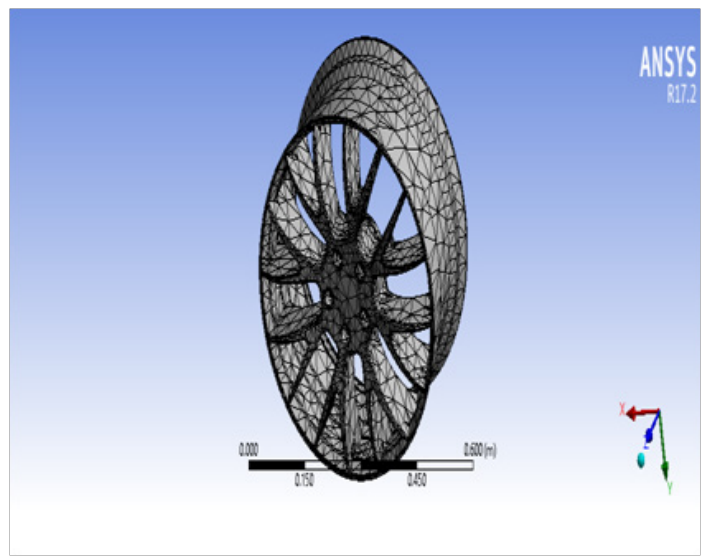

Figure 2 Meshed model.

\section{Displacements}

Translation in $\mathrm{x}, \mathrm{y}, \mathrm{z}$ directions were fixed.

Rotation in $\mathrm{x}, \mathrm{y}, \mathrm{z}$ direction was fixed.

Angular velocity in $\mathrm{X}$ direction is zero, $\mathrm{Y}$ direction is zero, and $\mathrm{Z}$ direction is $86.69 \mathrm{rad} / \mathrm{s}$

\section{Results and discussion}

\section{Results of static structural analysis on aluminium alloy material}

Here due to the displacement of the centre of the wheel rim is fixed, the amount of the deformation of the material in the centre is minimum and at the circumference of the wheel rim it is maximum with the value of $0.05 \mathrm{~mm}$ when load is increased which is shown in Figure 3.



Figure 3 Deformation on aluminium alloy material.

Due to the inflation pressure which is acting at the circumference of the rim wheel the stress induced there is maximum with the value of $14.41 \mathrm{MPa} .{ }^{9-12}$ The stress is very low at the centre of the rim due to the constrains used which is shown in Figure 4.

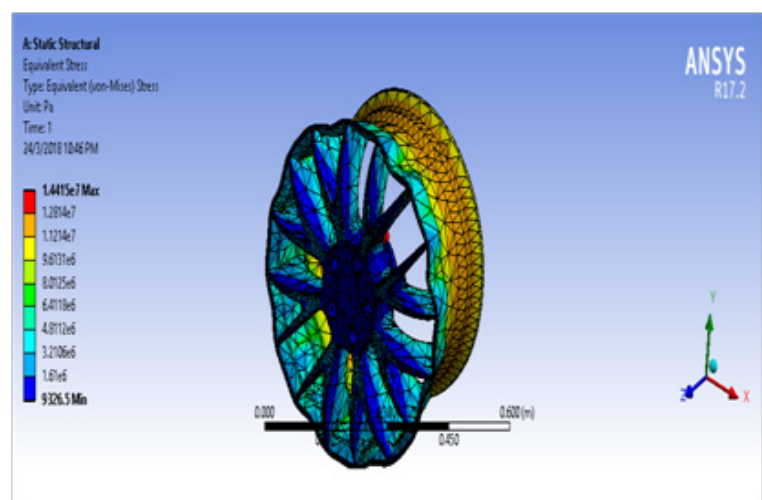

Figure 4 Von mises stress on aluminium alloy material.

The shear stress is maximum at the circumferential side of the rim which is nearer to the spokes connecting side and shear stress is minimum at the wheel centre which is shown in Figure 5.

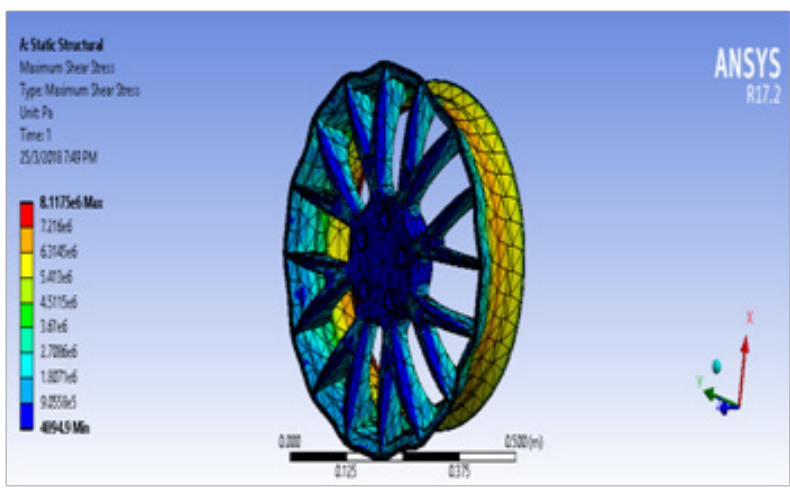

Figure 5 Maximum shear stress of Aluminium Alloy material.

Due to the various type of fatigue that occurs in the wheel rim the life of the wheel rim stays constant for all nodes and points the rim for the cycles of 1e6 which is shown in Figure 6. 


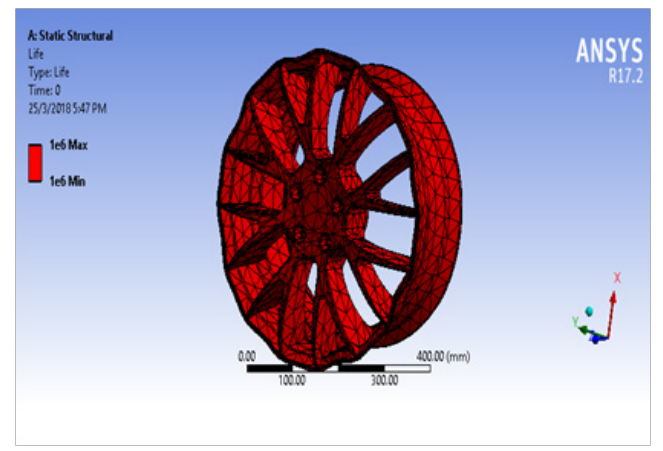

Figure 6 Life of aluminium alloy material.

\section{Results of PEEK material}

Pure composite PEEK material withstands the amount of the deformation of the material upto $0.93365 \mathrm{~mm}$ which is caused by the angular velocity and the inflation. The value obtained here is some lower than the aluminium alloy because of absence of the fine bonds which is shown in Figure 7.

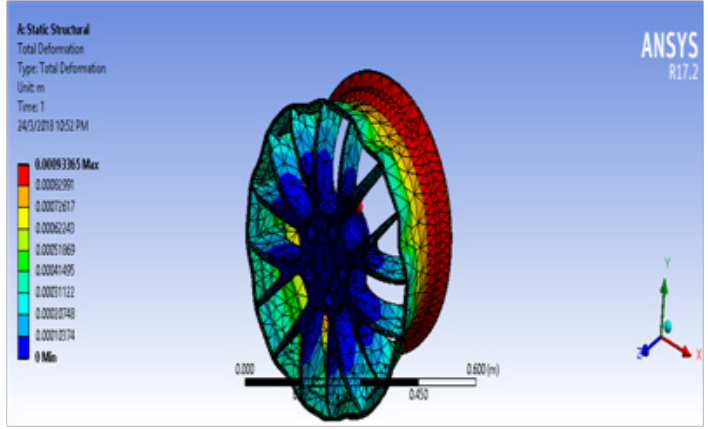

Figure 7 Deformation on PEEK material.

Due to the inflation pressure which is acting at the circumference of the rim wheel the stress induced there is maximum with the value of $14.35 \mathrm{MPa}$ and the minimum value of $0.008600 \mathrm{MPa}^{13-15}$ The stress is very low at the centre of the rim due to the constrains used which is shown in Figure 8.

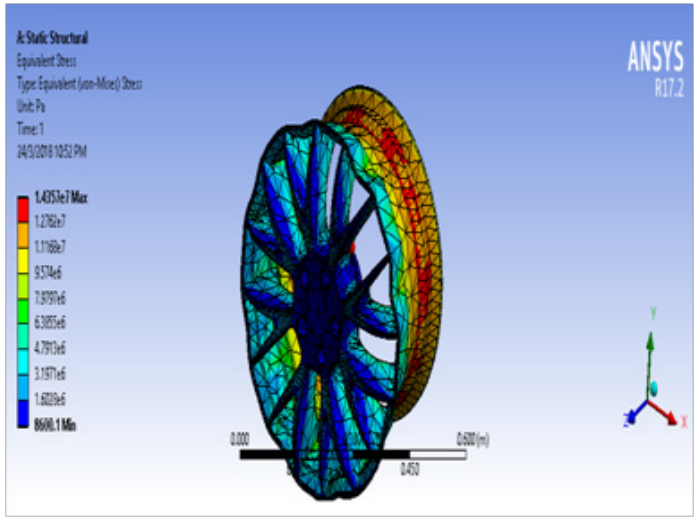

Figure 8 Von mises stress on PEEK material.

Due to the various type of fatigue that occurs in the wheel rim, the life of the wheel rim stays constant for all nodes and points the rim for the cycles of 1e6 which is shown in Figure 9.

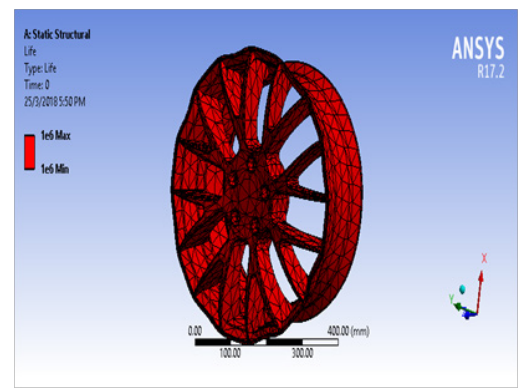

Figure 9 Life of PEEK material.

In the pure PEEK material, the maximum shear stress occurs at the inner circumference of the rim wheel in the back side with a value of 8.13MPa. The centre of the rim wheel and spokes experience a low shear stress with a value $0.016771 \mathrm{MPa}$ which is shown in Figure 10.



Figure 10 Maximum shear stress of PEEK material.

\section{Results of PEEK GF 30 material}

Due to the displacement of the centre of the wheel rim is fixed, the amount of the deformation of the material in the centre is minimum and at the outer circumference of the wheel rim it is maximum with the value of $0.93 \mathrm{~mm}$ which is shown in Figure 11.

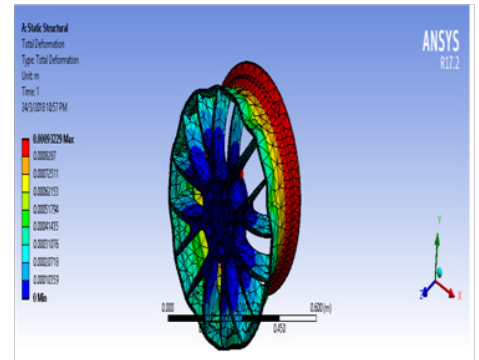

Figure II Deformation on PEEK GF 30 material.

PEEK GF30 which is composite material contains $30 \%$ of the glass fiber has a maximum von mises stress at the outer circumference of the wheel with a value of $14.38 \mathrm{MPa}$ which is shown in Figure 12.

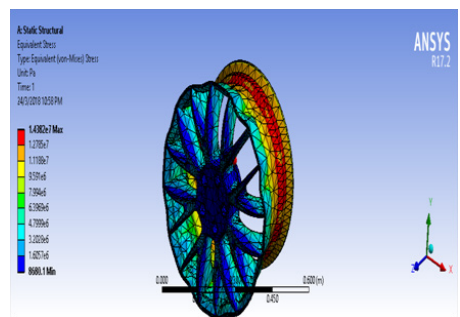

Figure 12 Von mises stress on PEEK GF 30 material. 
For the $1 \mathrm{e} 6$ cycles the wheels withstand the entire tear and the tear that is produced by the mechanical forces. The composite PEEK materials have the properties identical to the conventional types which are shown in Figure 13



Figure 13 Life of PEEK GF 30 material.

In the PEEK GF 30 the maximum shear stress occurs at the inner circumference of the rim wheel in the back side with a value of 8.14 $\mathrm{MPa}$. The centre of the rim wheel and spokes experience a low shear stress with a value $0.0158 \mathrm{MPa}$ which is shown in Figure 14.

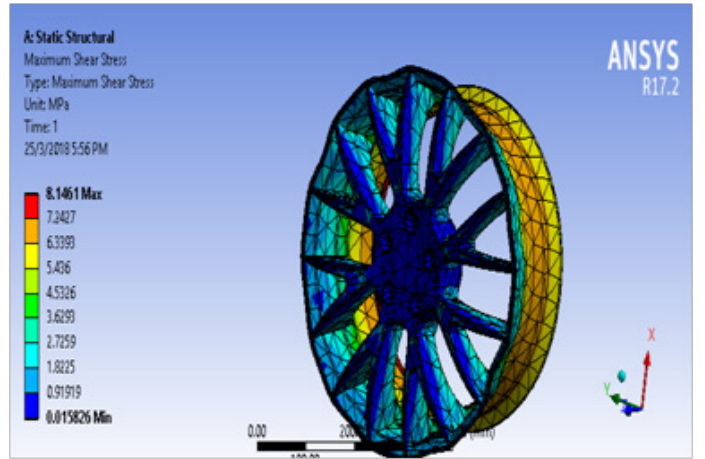

Figure I4 Maximum shear stress of PEEK GF 30 material.

\section{Results of PEEK 90 HMF 20 material}

In this material, the maximum amount of the material deformed will at the outer circumference of the wheel rim with the value of the $0.1732 \mathrm{~mm}$. The deformation of this wheel rim is almost identical to the aluminium alloy which is shown in Figure 15.

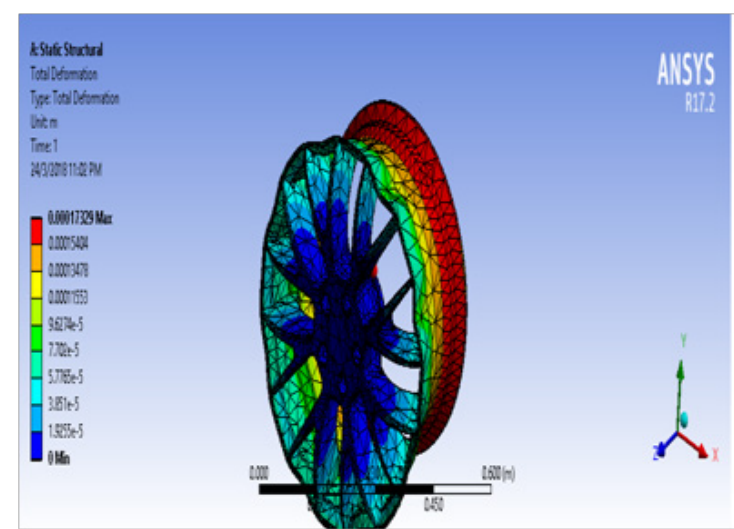

Figure I5 Deformation on PEEK 90 HMF 20 material.
The stress which is acting in combined three directions in this material acts maximum at the outer circumference of the wheel rim with the value of $14.386 \mathrm{MPa}$ which is shown in Figure16.

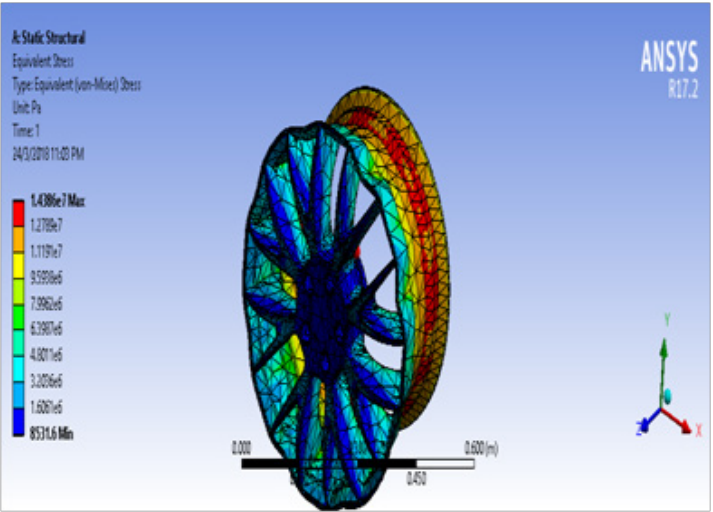

Figure I 6 Von mises sStress on PEEK 90 HMF 20 material.

In all the nodes and points of the rim the life is constant with the life cycles of $1 \mathrm{e} 6$ and no wear and tear make the rim failure upto this time which is shown in Figure 17.

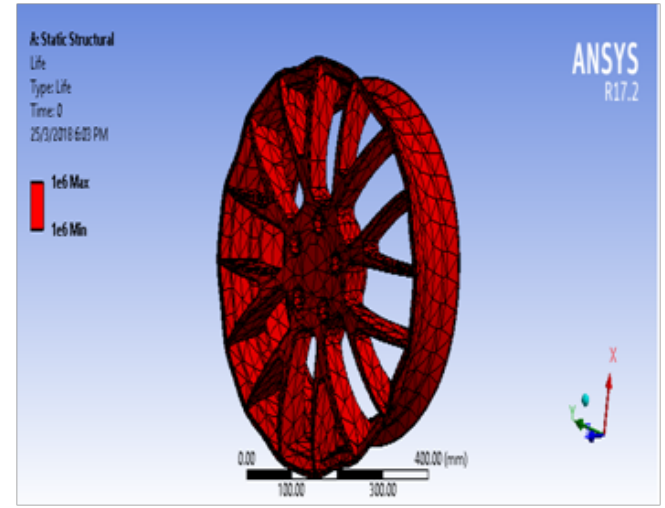

Figure 17 Life of PEEK 90 HMF 20 material.

Since PEEK 90HMF 20 has the identical property of aluminium alloy it has tendency to bear the maximum shear stress of value 8.1471MPa which is shown in Figure 18.

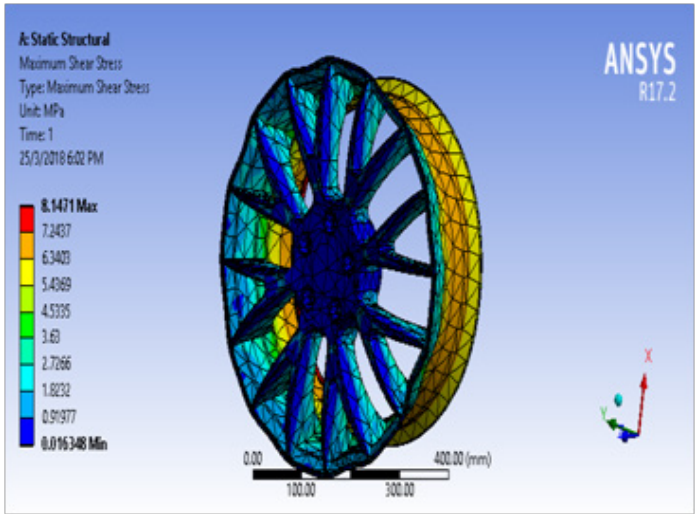

Figure 18 Maximum shear stress of PEEK 90 HMF 20 material. 


\section{Results of PEEK 90 HMF 40}

This high modulus carbon fiber reinforced PEEK material has the maximum deformation at the outer circumference of the rim wheel with a value of $0.85 \mathrm{~mm}$ when the angular velocity is in $\mathrm{z}$-direction which is shown in Figure 19.

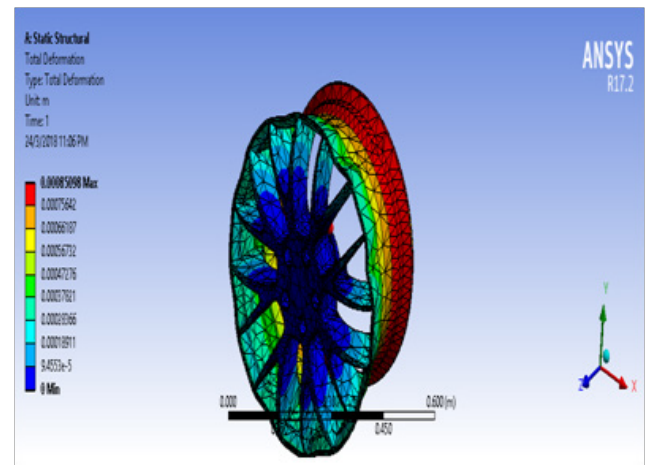

Figure 19 Deformation on PEEK 90 HMF 40 material.

When the angular velocity of the rim with respect to $\mathrm{x}$ and $\mathrm{y}$ direction is zero, the equivalent stress acts maximum at the back side of outer circumference of the rim wheel with a value of $14.28 \mathrm{MPa}$ which is shown in Figure 20.



Figure 20 Von mises stress on PEEK 90 HMF 40 material.

\section{Analysis results}

On interpreting the following results we find that PEEK GF 30 is the weightless material (Table 4) among the filtered PEEK material .In case of deformation, all those materials get deform about the point of loading when the load increased the rim would deform more but among those materials the PEEK 90 HMF 20 stands the best than
For the $1 \mathrm{e} 6$ cycles the wheel withstands all the wear and the tear that is produced by the mechanical forces upto $1 \mathrm{e} 6$ cycles. This composite PEEK material has the properties identical to the conventional types which are shown in Figure 21.

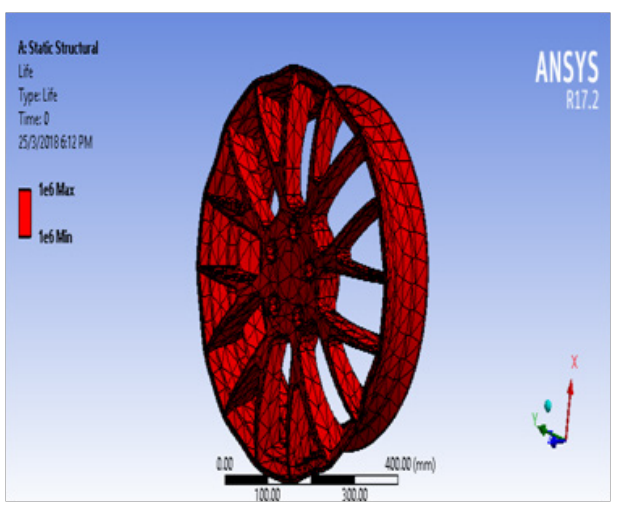

Figure 2I Life of PEEK 90 HMF 40 material.

The mechanical forces cause the rim wheel to produce the shearing forces which in turn produces the maximum shear stress in the inner circumference of the wheel with the value of $8.053 \mathrm{MPa}$ and minimum at the centre of the wheel rim which is shown in Figure 22.



Figure 22 Maximum shear stress of PEEK 90 HMF 40 material.

other peek materials, where the deformation is low comparatively .On considering von mises stress all materials show similar properties nearer to the same obtained values. And also while interpreting the life cycle, all materials withstand the given life of $10 \mathrm{e} 6$ cycles so that we have to select the material based on the weight property consideration..$^{16,17}$

Table 4 Results of materials

\begin{tabular}{llllll}
\hline SI No & Material & Weight, $\mathbf{W}(\mathbf{k g})$ & Deformation, $\boldsymbol{x}(\mathbf{m m})$ & Von mises Stress, $\boldsymbol{\sigma}(\mathbf{M P a})$ & Life $(\mathbf{c y c l e})$ \\
\hline $\mathrm{I}$ & Aluminium Alloy & 15.761 & 0.052 & $14.4 \mathrm{I}$ & $1.00 \mathrm{E}+07$ \\
2 & PEEK & 8.922 & 0.934 & 14.43 & $1.00 \mathrm{E}+07$ \\
3 & PEEK GF 30 & 7.748 & 0.932 & 14.38 & $1.00 \mathrm{E}+07$ \\
4 & PEEK 90 HMF 20 & $8.04 \mathrm{I}$ & 0.173 & 14.38 & $1.00 \mathrm{E}+07$ \\
5 & PEEK 90 HMF 40 & $8.5 \mathrm{II}$ & 0.851 & 14.28 & $1.00 \mathrm{E}+07$ \\
\hline
\end{tabular}




\section{Conclusion}

Finite Element analysis of the four wheeler rim using Aluminium alloy and PEEK Composites has been done using ANSYS Workbench. The life cycle prediction helps to identify the durability of the material. The rim was modeled as per standards and analyzed for different materials such as Aluminium Alloy, PEEK (Polyether ether ketone), PEEK with 30\% Glass fiber, PEEK-90 HMF 20, PEEK-90 HMF 40. From obtained results optimization was carried out.

The weight of rim is reduced from $15.761 \mathrm{Kg}$ to $7.748 \mathrm{Kg}$ while using PEEK GF 30 material when compare to Aluminium Alloy material. However, the deformation and stress of PEEK 90 HMF 20 material is nearly to Aluminium alloy material. The weight of PEEK 90 HMF 20 material is $8.041 \mathrm{~kg}$. Finally from the results it is clear that PEEK 90HMF20 is best material to replace Aluminium Alloy (A356.2) material owing to reliability and safety aspects.

\section{Acknowledgments}

None.

\section{Conflict of interest}

Author declare there is no conflict of interest.

\section{References}

1. Emmanuel M Adigio, Ebughni O Nangi. Computer Aided Design and Simulation of Radial Fatigue Test of Automobile Rim Using ANSYS. IOSR Journal of Mechanical and Civil Engineering (IOSR-JMCE). 2014;11(1):68-73.

2. Satyanarayana N, Sambaiah CH. Fatigue Analysis of Aluminum Alloy Wheel under Radial Load. International Journal of Mechanical and Industrial Engineering (IJMIE). 2011;2(1).

3. Yadav PH, Ramdasi PG. Optimization of Car Rim Using OptiStruct. IOSR Journal of Environmental Science, Toxicology and Food Technology (IOSR-JESTFT). 2012;2(3):10-15.

4. Meghashyam P, Girivardhan Naidu S, Sayed Baba N, et al. Design and Analysis of Wheel Rim using CATIA \& ANSYS. International Journal of Application or Innovation in Engineering \& Management (IJAIEM). 2013;2(8).

5. Ganesh S, Periyasamy P. Design and Analysis of Spiral Wheel Rim for Four Wheeler. The International Journal Of Engineering And Science (IJES). 2014;3(4):29-37.

6. Vikranth Deepak S, Naresh C, Syed Altaf Hussain, et al. Modelling and Analysis of Alloy Wheel for Four Wheeler Vehicle. International Journal of Mechanical Engineering and Robotics Research (IJMERR). 2012;1(3).

7. Sunil N Yadav, Hanamapure NS. Analyze the Effect of Camber Angle on Fatigue Life of Wheel Rim of Passenger Car by Using Radial Fatigue Testing. International Journal of Engineering Science and Innovative Technology (IJESIT). 2013;2(5).

8. Siva Prasad T, Krishnaiah T, Iliyas J, et al. A Review on Modelling and Analysis of Car Wheel Rim using CATIA \& ANSYS. International Journal of Innovative Science and Modern Engineering (IJISME). 2014;2(6).

9. Suwarna Torgal, Swati Mishra. Stress Analysis of Wheel Rim. International Journal of Mechanical Science and Engineering (IJMER). 2012;1(1).
10. Rahul K Jape, Jadhav SG. CAD Modeling and FEA Analysis of Wheel Rim for Weight Reduction. International Journal of Science and Computing. 2016;6(6).

11. Kalpesh R Salunkhe, Shailesh S Pimpale. Design, FEM Analysis and of Alloy Wheel Rim of a Four Wheeler. International Advanced Research Journal in Science, Engineering and Technology. 2017;4(9).

12. Sourav Das. Design and Weight optimization of Aluminium Alloy Wheel. International Journal of Scientific and Research Publications. 2014;4(6).

13. Ravi Lidoriya, Sanjay Chaudhary, Anil Kumar Mohopatra, et al. Design and Analysis of Aluminium Alloy Wheel using PEEK Material. International Journal of Mechanical Engineering and Research. 2013;3(5).

14. Karthik AS, Praveen S Ullagaddi, Sangangouda P, et al. Static Analysis of Alloy Wheel using FEA. International Journal for Innovative Research in Science and Technology (IJIRST). 2016;2(12).

15. Sivakrishna V, Bala bashker J. Impact Analysis of Aluminium Alloy Wheel. International Journal and Magazine of Engineering, Technology, Management and Research. 2014;1(12).

16. Sasank Shekhar Panda, Dibya Narayan Behera, Satya Narayan Tripathy, et al. Modeling and Structural Analysis of Alloy Wheel Using ANSYS. International Journal of Engineering Science \& Research Technology. 2016.

17. Si Young Kwak, Jie Cheng, Jeong Kil Choi, et al. Impact Analysis of Casting Parts Considering Shrinkage Cavity Defect. China Foundry. 2011;8(1):112-116. 